\title{
A Hermeneutic Approach utilizing Interactive Visual Communication to Enhance Speech and Spelling for Dyslexic Children in Malaysia Primary Schools
}

\author{
Adrina Che kamarudin, Ruslan Abdul Rahim \\ ${ }^{1}$ Faculty of Art and Design, Universiti Teknologi MARA, 40450 Shah Alam, Selangor, Malaysia \\ adrina.andrey@yahoo.com, rusr2001@yahoo.com
}

\begin{abstract}
Based on earlier studies on visual communication issues, many have suggested improving "language, syllable, or phonetics" to enhance speech and spelling for dyslexic children. The objectives are: 1) to identify visual communication by integrating the learning through text and voice instructions; 2) to analyse the visual communication in the syllables of Bahasa Melayu. Results and findings from the two objectives in this study will form the latest learning platform for dyslexic children and the other learning language disorders of children as a medium for learning the syllables of Bahasa Melayu.
\end{abstract}

Keywords: Dyslexia, Hermeneutic, Interactive Visual Communication, Speech and Spelling.

eISSN: 2398-4287@ 2021. The Authors. Published for AMER ABRA cE-Bs by e-International Publishing House, Ltd., UK. This is an open access article under the CC BYNC-ND license (http://creativecommons.org/licenses/by-nc-nd/4.0/). Peer-review under responsibility of AMER (Association of Malaysian Environment-Behaviour Researchers), ABRA (Association of Behavioural Researchers on Asians/Africans/Arabians) and cE-Bs (Centre for Environment-Behaviour Studies), Faculty of Architecture, Planning \& Surveying, Universiti Teknologi MARA, Malaysia.

DOI: https://doi.org/10.21834/ebpj.v6iSI4.2894

\subsection{Introduction}

As Piotrowska and Willis (2019) mentioned, cognitive processes or basic perceptual do not represent the cause of dyslexia, it may be that phonological difficulty but are secondary. Peterson and Pennington (2015) stipulated that characterised developmental dyslexia is by the inability to write skills and reading to develop neurotypical levels despite unimpaired adequate educational opportunities and fluid intelligence. An average of nearly $5-9 \%$ of the population is dyslexic reading a severe deficit (Shaywitz \& Shaywitz, 2005). In improving the United States' legal situation, dyslexia is getting more attention by education professionals because of the often inaccurate verbs produced and dyslexia is the term ever avoided (Gonzalez \& Brown, 2019).

For more than a hundred years, many theories to explain the nature of this learning disorder and dyslexia attract researchers' interests throughout the world to produce research (Snowling, 2012). The definition of goodness or a definition of universal dyslexia does not exist by the International Dyslexia Association [IDA] (International Dyslexia Association, 2018). International Dyslexia Association (2018) defines dyslexia as neurobiological in the origin of specific learning disability. It is characterised by poor decoding and spelling abilities and difficulties with fluent or accurate word recognition.

\subsection{Literature Review}

The provision of effective classroom instruction and relation to other cognitive abilities are often difficulties that often result from a deficit in the language phonological component. A reduced reading experience that can impede background knowledge and vocabulary growth

eISSN: 2398-4287@ 2021. The Authors. Published for AMER ABRA cE-Bs by e-International Publishing House, Ltd., UK. This is an open access article under the CC BYNC-ND license (http://creativecommons.org/licenses/by-nc-nd/4.0/). Peer-review under responsibility of AMER (Association of Malaysian Environment-Behaviour Researchers), ABRA (Association of Behavioural Researchers on Asians/Africans/Arabians) and cE-Bs (Centre for Environment-Behaviour Studies), Faculty of Architecture, Planning \& Surveying, Universiti Teknologi MARA, Malaysia.

DOI: https://doi.org/10.21834/ebpj.v6iSI4.2894 
may include problems in reading comprehension in secondary consequences. However, all poor readers are not seen from phonological awareness deficits (Ramus \& Ahissar, 2012). Youman \& Mather (2018) found that "Today, laws continue to focus primarily upon: a) dyslexia awareness, b) pilot programs for screening and intervention, c) teacher training, d) provision of interventions and accommodations, and e) the overall rights of individuals with dyslexia" was mentioned from Dyslexia Laws in the USA (p. 37). As Satina Maria Moktar (2013) states, "In fact, dyslexic children have better intellect than normal children".

Satina Maria Moktar added that "In the year 2012, one of her alumni student from Program Pendidikan Khas Integrasi (PPKI) named Anis Adila Sofea has proven her success and ability in the Ujian Pendidikan Sekolah Rendah (UPSR) for achieving good results of 4A and $1 \mathrm{~B}$ despite her dyslexia". Teachers give a strong emphasis on empowering the Malay Language because dyslexic children need to be proficient in using the Malay Language first before learning other languages such as English, Mandarin, and others language because the Malay Language is the National Language Malaysia. When children with dyslexia are fully controlling the Malay Language, it makes them easier to master other languages (Nik Kamila Mamat, 2016).

According to Subramaniam, Mallan, \& Mat (2013), approximately $10 \%-15 \%$ of the world's population has dyslexia based on statistics reported by the International Dyslexia Association in 2010. Subramaniam et al. (2013) said that about 314,000 children in Malaysia had dyslexia as stated by the Ministry of Education Malaysia and every 20 students mentioned one case of dyslexia. About $0 \%-15 \%$ of primary school children experience dyslexia in Malaysia, as stated by the Malaysian Harmonic Social Association (PSHM) in their research. It is reported that $25 \%$ in Malaysia, out of 2 million people with dyslexia are among students (Subramaniam et al., 2013).

Nor Hasbiah Ubaidullah (2007) stipulated that about 314,000 school children in Malaysia have dyslexia while dyslexia in Malaysia is classified as Disabled Learning Specific (SLD) as reported in 2005. The system of interventions and population size are the real needs. Providing help and support through functions designed in multimedia software can help children with disabilities use sound and visual abilities to help students with dyslexia. Multimedia software with visuals, sounds, short stories, intuitive capabilities, and games can help showcase Malay folklore for dyslexic children. Increased use of interactive media software such as learning applications has been found to help dyslexic children in Malaysia.

Henriksson \& Friesen (2012) stated hermeneutics is the art and science of meaning and interpretation. According to Lindseth \& Norberg (2004), hermeneutics is classified with the study of texts and the description of life experiences in the text should be interpreted for their purposes.

\subsection{Methodology}

The methodology utilised is field interviews with the dyslexia teachers in specialised program classes. The accurate information and resources about dyslexic children in this study began with the interviews in the two different schools in urban and rural areas. There are a few perceptions of dyslexic children and teachers. This study has two types of data collection method, which are primary data and secondary data. In both types of data collection, they consist of qualitative and quantitative research methods. In this study, qualitative and quantitative research methods are field interview, participant observation, sampling, surveys and questionnaires, and experimental design for dyslexic children (learning application testing).

This study uses two types of research methodology: the qualitative and quantitative method as the medium for accurate and correct data collection, as shown in Fig. 1. The first method used is qualitative such as field interview in specialised program classes, participant observation, which requires researchers to participate when dyslexic children are tested with learning applications in school. The researchers also attended a learning class of dyslexic children at the school, and the last method used in qualitative is data archival such as books, journal articles, newspaper, and the internet. The next quantitative method is surveys and questionnaires, and experimental design includes three tests: the existing test, pre-test, and post-test.

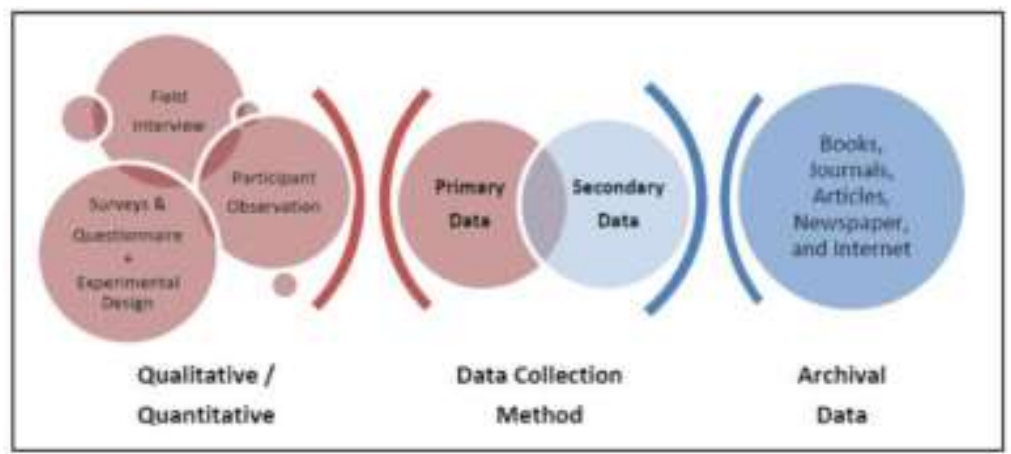

Fig. 1: Method Framework for Data Collection

(Source: Adrina Che Kamarudin, 2019)

\subsection{Primary Data}

Four main methods are used in this study to collect primary data by deciding the result based on the data needed. The methods used are field interview, participant observation, surveys and questionnaires, and the last method is experimental design. The word survey has become the most frequently associated with questionnaires because the interview method is also a survey. Generally, it is assumed 
that a questionnaire is involved when someone says 'I'm carrying out a survey'. It is more or less the same as those when using questionnaires as the objectives when they carry out interviews. Arnold, Robertson, \& Cooper (1991) found that 'talking questionnaire' often used as the interview. However, two different approaches from the techniques are used, such as interview techniques and questionnaire. Unlike interviews or questionnaires, the participant observation method does not answer the respondents because it collects the data about children's behaviour. The researcher records and observes the children's behaviour that is relevant to this study. As Jankowicz (1995) mentioned, step-by-step procedures are the contrastive techniques to analyse the information and to follow to gather data they contain. This study develops skills to understand learning application of the methods that are used when employing a particular method. Perhaps at this stage technique and process should be distinguished.

\subsection{Secondary Data}

A stated by Yegidis \& Weinbach (2002), a variety of methods can be analysed the data either qualitative or more commonly of quantitative. Popular culture represents films, tapes, television programs, magazine articles, and photographs for analysis and examination. They can be examined using the portrayal of women and men, Caucasians and people of colour, content analysis to compare, of people with disabilities and other people, and various sociocultural groups. Magazines, journals, newspapers, and films such as the vehicles in the content analysis involve careful examination of human communication. Public documents all provide a rich source of data about people, textbooks, newspaper articles, and research papers are written records. These sources can be very informative.

\subsection{Hermeneutic Method}

Henriksson \& Friesen (2012) stated hermeneutics is the art and science of meaning and interpretation. According to Lindseth \& Norberg (2004), hermeneutics is classified with the study of texts, and the description of life experiences in the text should be interpreted for their purposes. This study also incorporates three methods to analyse the data to obtain clear and precise information. This study's analysis methods are a comparative analysis, statistical analysis, and the analysis of formalism. In this study, the comparative analysis was made to compare field interviews, participant observation, and statistical analysis. Statistical analysis is also used to get dyslexic students' findings, existing application testing, pre-test, and post-test for new learning application named "Cerdik Media".

\subsection{Findings}

This study has visualised the existing applications locally and abroad. The existing apps selected are 'Alphabetics' (International) and 'Didik Manja' (Local). Some of the problems with existing and domestic applications are colour, typography, background, description, cartoon characters, and navigation buttons. Existing applications do not consider issues of improvement or uniformity for children with disabilities for their learning and interest. The selected international application is "Alphabetic", and the selected local application is "Didik Manja".

\subsection{International and Local Existing Application}

Based on Table 1 and Table 2, inconsistent typography and layout designs in non-user-friendly applications for dyslexic children are used in existing applications both inside and outside the country. Existing applications do not reflect their identity. The overall colour used in the app is not appealing as it looks too faded or very soft and does not interest dyslexic children. No symbolic use of images with messages and layout of incomplete application buttons and layouts are used. Selected appropriate and convenient application buttons also affect dyslexic children to self-study without supervision. The existing app uses a brightly coloured layout background filled with patterns without any additional layout that helps the learning process. The typography also is not easy to understand for dyslexic children as there is some confusion, making it difficult for dyslexic children to review the learning using the application.

Table 1. Visual Analysis of Local Application "Didik Manja"

\begin{tabular}{|l|l|l|}
\hline \multicolumn{1}{|c|}{$\begin{array}{l}\text { Description: This page (Huruf Vokal) has a single font } \\
\text { and images for vocal learning, which used at the } \\
\text { beginning of the word. }\end{array}$} & $\begin{array}{l}\text { Background: Use a white background for easy } \\
\text { identification of image and vowels. }\end{array}$ \\
\cline { 2 - 4 } & $\begin{array}{l}\text { Navigation Button: Have a previous button, next, } \\
\text { home, and menu button on the image of learning. }\end{array}$ & $\begin{array}{l}\text { Cartoon Character: The use of illustrations in the } \\
\text { learning picture to attract children. }\end{array}$ \\
\hline
\end{tabular}

(Source: Adrina Che Kamarudin, 2019) 
Table 2: Visual Analysis of International Application "Alphabetics"

\begin{tabular}{|l|l|l|}
\hline \multirow{2}{*}{4} & $\begin{array}{l}\text { Description: This page is a learning allows children to } \\
\text { learn the difference between uppercase and } \\
\text { lowercase letters. }\end{array}$ & $\begin{array}{l}\text { Background: The use of white colours as colour } \\
\text { background on this application. }\end{array}$ \\
\cline { 2 - 4 } & $\begin{array}{l}\text { Navigation Button: Have a home button, star to draw } \\
\text { the letters, and the correct pronunciation button. }\end{array}$ & $\begin{array}{l}\text { Typography: Use small and large letters using bold } \\
\text { type together with an interesting font color. }\end{array}$ \\
\cline { 2 - 3 } & Colour: Most of the colours that used in this application was enjoyable and colorful for children. \\
\hline
\end{tabular}

(Source: Adrina Che Kamarudin, 2019)

\subsection{Discussion}

Among the problems encountered and identified in existing applications are typography, layout backgrounds, navigation buttons, theme colours, cartoon characters, and learning descriptions. Can be seen from Fig. 2, dyslexic children are being explained by the researcher on existing applications that are unclear and confuse them. Existing applications that have been published to the public should concern the issues of the stated features and create user-friendly applications that are identified first.

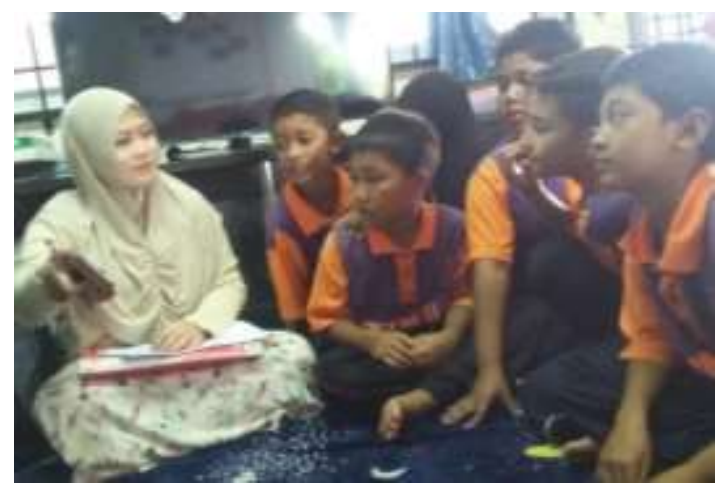

Fig. 2: Existing applications that are unclear and confuse them (Source: Adrina Che Kamarudin, 2019)

The objectives of this study were achieved in helping dyslexic children identify visual communication by integrating learning through texts and voice commands. Next can analyse visual communication in Malay syllable, and then dyslexic children can speak and spell well. Finally, the objective in developing the latest learning platform can be achieved to help dyslexic children in their speech and spelling in Malay Language syllabus learning. Interactive learning apps are required for dyslexic children as they need additional help, especially in today's interactive technology era. Based on Fig. 3, new interactive learning applications are developed.

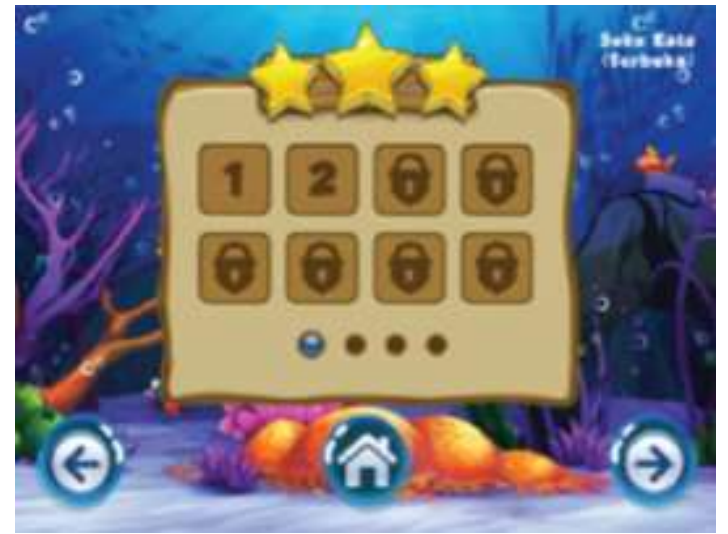

Fig. 3: New applications "Cerdik Media" (Source: Adrina Kamarudin, 2019)

Fig. 4, showing statistical results from the new application. The highest percentage is very satisfactory from the overall aspect of the application, which is $83 \%$. Improvements in all aspects, including navigation buttons and layout design, can be accurately assessed by dyslexic children in application development. Fig. 6 can also be seen that the role of colour and design of the application plays an 
essential role in attracting dyslexic children. Both of these elements have as much as $58 \%$ good percentage of statistical equations. Dyslexic children are very interested and easily attracted to cheerful music and colourful backgrounds compared to other applications that do not have these features.
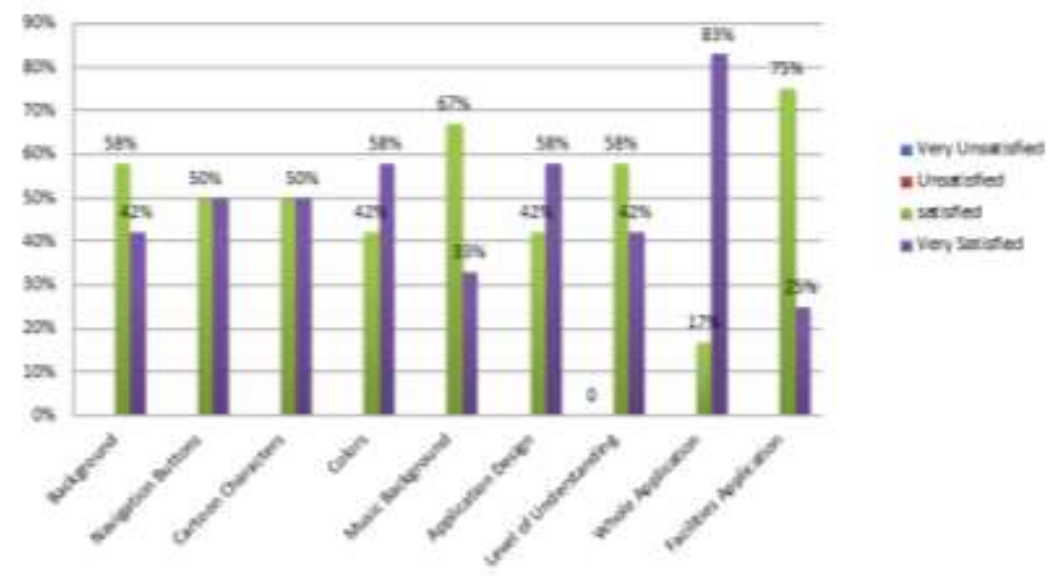

Fig. 4: New applications "Cerdik Media" (Post Test) (Source: Adrina Kamarudin, 2019)

This study provides new learning applications that have user-friendly features and games in the application to it more fun to help dyslexic children spell and speak fluently for Malay syllable learning. Existing application in the local and international are layout design used in the application is disproportionate, and there is also inconsistent use of typography. The colours used in the application are not attractive and do not reflect their own identity. The application's layout is messy, and none symbolic images with the message to be conveyed were used. The typography used is not clear, and the background used bright colour and full of pattern.

\subsection{Conclusion \& Recommendations}

In this paper, the researcher examines the approach involved in providing interactive visual communication guides in learning and assisting dyslexic children who are weak in spelling and speech in Malay syllables. This study successfully developed interactive visual communication applications and helped dyslexic children in spelling and speech learning, especially the Malay syllabus. Hopefully, this study will open up novel opportunities for a new learning platform in Bahasa Melayu's syllables based on visual communication that has a large contribution to the teaching \& learning for dyslexic children in special program classes.

This study is aligned with meeting the government's policy, as stated within the Education Act 1996 in Malaysia's Federal Constitution. Some interpretations and discoveries have also produced interactive visual communication applications and learning methods. Through data analysis, there are weaknesses in the spelling and speech of dyslexic children in the Malay syllable. Besides, existing applications do not have simple and clear voice instructions that can facilitate dyslexic children in their Malay syllable learning.

In conclusion, interactive visual communication applications in the new Malay syllable with features such as clear voice commands, textual instructions, easy buttons, layout design and interesting music used are developed to help dyslexic children in Malay syllabus learning. With all the features of user-friendly applications for dyslexic children, they can study themselves without or with teacher supervision.

Our next research proposes a complete Business Model Canvas, which is Need, Approach, Benefits, and Competition (NABC). New support models should be created in the Business Model Canvas (NABC) for dyslexic children. The complete Business Model Canvas (NABC) in the creative technology industry (visual communication interactive application) today will see a lot of competition in the application of developers and in competition to develop applications solutions for others' learning problems.

\section{Acknowledgements}

First of all, the authors are pleased to extend thanks to the lecturers, friends, and family for their valuable assistance and support in completing this project. The authors would also like to thank the University Technology Mara (UiTM) Shah Alam, Selangor. Finally, special thanks to the Institute of Research Management and Innovation (IRMI) of Universiti Teknologi Mara Shah Alam. This study is supported by UiTM Research Grant No. 600-IRMI 5/3 / GIP (073/2018).

\section{References}

Arnold, J. M., Robertson, I. T., \& Cooper, C. L. (1991) Work Psychology: Understanding human behaviour in the workplace, 2nd ed. London: Pitman.

Amy, B., Rodney, R., \& Sandra, L. (2002) Children in The Digital Age. (Influences of Electronic Media on Development), London : Greenwood Publishing Group Inc. 
Dorothy, G., \& Jerome, L. (2001) Handbook of Children and The Media, United States of America: Sage Publication.

Gonzalez, M., \& Brown, T. B. H. (2019). Early Childhood Educators' Perceptions of Dyslexia and Ability to Identify Students At-Risk. Journal of Education and Learning, Vol. 8, No. 3; 2019. 1-12. https://doi.org/10.5539/jel.v8n3p1

Henriksson, C., \& Friesen, N. (2012). Hermeneutic Phenomenology. In N. Friesen, C.

Henriksson, \& T. Saevi (Eds.), Hermeneutic phenomenology, 1-14. https://doi.org/10.1007/978-94-6091-834-6_7

International Dyslexia Association. (2018). Dyslexia law status by state. March 2018 update. Retrieved from https://dyslexiaida.org/dyslexia-laws-status-by-state/ Jankowicz, A. D. (1995) Business Research Projects, 2nd ed. London: Chapman and Hall.

Lindseth, A., \& Norberg, A. (2004). A phenomenological hermeneutical method for researching lived experience. Scandinavian Journal of Caring Science, 18(2), 145-153. https://doi.org/10.1111/j.1471-6712.2004.00258.x

Nik Kamila Mamat, Personal Interview in Sekolah Kebangsaan Tengku Mahmud 2. Besut, Terengganu, 20 October 2016.

Nor Hasbiah Ubaidullah (2007). Perisian Kursus Multimedia dalam literasi Matematik (D-Matematika) untuk pelajar disleksia. Ph.D Thesis, Universiti Kebangsaan Malaysia.

Ott, P. (1997) How to detect and manage dyslexia, London: Heinemann Educational Publishers.

Peterson, R. L., \& Pennington, B. F. (2015). Developmental Dyslexia. Annual Review of Clinical Psychology, 11, 283-307. Retrieved from www.annualreviews.org

Piotrowska, B., \& Willis, A. (2019). Beyond the global motion deficit hypothesis of developmental dyslexia: A cross-sectional study of visual, cognitive, and socio-economic factors influencing reading ability in children. Journal of Vision Research, 159 (2019) 48-60. https://doi.org/10.1016/j.visres.2019.03.007.

Ramus, F., \& Ahissar, M. (2012). Developmental dyslexia: The difficulties of interpreting poor performance, and the importance of normal performance, Cognitive Neuropsychology, 29:1-2, 104-122. http://dx.doi.org/10.1080/02643294.2012.677420

Satina Maria Moktar, Personal Interview in Sekolah Kebangsaan Padang Hiliran. Kuala Terengganu, 13 October 2013.

Shaywitz, S. E., \& Shaywitz, B. A. (2005). Dyslexia (specific reading disability). Biological Psychiatry, 57(11), 1301-1309. https://doi.org/10.1016/j.biopsych.2005.01.043

Snowling, M. J. (2012). Changing concepts of dyslexia: Nature, treatment and co-morbidity. Journal of Child Psychology and Psychiatry, 53:9 (2012), pp e1-e3. https:// doi:10.1111/j.1469-7610.2009.02197.x

Subramaniam, V., Mallan, V. K., \& Mat, N. H. C. (2013). Multi-senses explication activities module for dyslexic children in Malaysia. Asian Social Science, 9(7), 241-267. http://dx.doi.org/10.5539/ass.v9n7p241

World Federation of Neurology (1968) Report of Research Group on Developmental Dyslexia and World Illiteracy, Bulletin of the Orton Society, pp. 21 - 22.

Yegidis, B. L., \& Weinbach, R. W. (2002) Research Methods for Social Workers, 4th Ed. Boston: Allyn \& Bacon.

Youman, M., \& Mather, N. (2018). Dyslexia laws in the USA: A 2018 update. Perspectives on Language and Literacy, 41, 37-41. Retrieved from www.DyslexialDA.org 